\title{
HPLC ANALYSIS OF HUMAN URINE FOR OXALATE CONTENT
}

\author{
MANGESH V. SURYAVANSHIa, SWAPNIL D. JADHAVb, RAHUL P. GUNEc, MANISH S. BHATIA*b, \\ YOGESH S. SHOUCHEa
}

\begin{abstract}
aMicrobial Culture Collection, National Centre for Cell Science, NCCS Complex, University of Pune Campus, Ganeshkhind, Pune 411007 (M. S.), India, bDepartment of Pharmaceutical Chemistry, Bharati Vidyapeeth College of Pharmacy, Kolhapur 416013 (M. S.), India, cDepartment of Urology, RCSM Govt. Medical College, CPR Hospital Compound, Bhausingji Rd, Kolhapur 416002 (M. S.), India Email: manish.bhatia@bharatividyapeeth.edu

Received: 31 May 2016 Revised and Accepted: 05 0ct 2016
\end{abstract}

\begin{abstract}
Objective: In the present communication, development and validation of reverse phase-high performance liquid chromatography method have been carried out for estimation of oxalate content in the urine of human volunteers with recurrent kidney stone disease and healthy status.

Methods: The analysis of oxalic acid has been carried out on KYA TECH HiQ Sil $\mathrm{C}_{18} \mathrm{HS}$ column using a mobile phase of methanol: $0.001 \mathrm{~N}$ acetic acid in water (50:50, v/v) with a flow rate of $1 \mathrm{ml} / \mathrm{min}$ and detection wavelength, $237 \mathrm{~nm}$.

Results: Analysis of oxalate content was carried out using single point calibration method with retention at 2.705 min with good resolution parameters. Urine sample collected from kidney stone patients and healthy volunteers over the period of $24 \mathrm{~h}$ were analyzed and it has been found that concentration of oxalate in healthy volunteers is less than $12 \mu \mathrm{g} / \mathrm{ml}$ whereas that in case of kidney stone patients is in the range of 39-151 $\mu \mathrm{g} / \mathrm{ml}$ and this data can be utilized for further interpretations about oxalate content in healthy and kidney stone diseased volunteers. This method was validated as per united states food and drug administration (USFDA) guidelines by the study of accuracy, precision, linearity, range, selectivity, the lower limit of quantitation, extraction recovery studies and stability studies for determining oxalate content in the urine of human volunteers. As relative standard deviations of oxalate content estimated are less than 5 percent, the method can be claimed accurate, precise, sensitive and selective for determining oxalate content in the urine of human volunteers.
\end{abstract}

Conclusion: The results are satisfactory, proving the effectiveness of the method for analysis of oxalate content from other biological fluids with few optimizations.

Keywords: HPLC, Kidney stone, Oxalate, Urine, USFDA

(C) 2016 The Authors. Published by Innovare Academic Sciences Pvt Ltd. This is an open access article under the CC BY license (http://creativecommons.org/licenses/by/4. 0/) DOI: http://dx.doi.org/10.22159/ijpps.2016v8i12.13168

\section{INTRODUCTION}

Calcium oxalate is a chemical compound that forms envelope-shaped crystals, known in plants as raphides. It is a major constituent of human kidney stones, and also found in beer stone, a scale that forms on containers used in breweries. Its chemical formula is $\mathrm{CaC}_{2} \mathrm{O}_{4}$ or $\mathrm{Ca}(\mathrm{COO})_{2}$. Calcium oxalate crystals in the urine are the most common constituent of human kidney stones, and calcium oxalate crystal formation is also one of the toxic effects of ethylene glycol poisoning [1]. But kidneys stone will occur in hypercalcemia or hyperoxalemia. It will be a big question as various factors like age, gender, diet will be responsible for hyperoxaluria in the form of kidney stones [2-4]. In hypercalcemia or hypoxaemia, excess calcium or oxalate will be present in urine, but the formation of calcium oxalate crystals also depends upon various types of factors like the saturation of urine with both components [5]. About $10 \%$ of people will experience nephrolithiasis in their lifetime, and about $70 \%$ of those will have recurrences. About $80 \%$ of stones are calcium based, and out of these, $80 \%$ of those are calcium oxalate stones [6].

Various types of factors like $\mathrm{pH}$, sample collection process parameters, the concentration of ascorbic acid are found to affect the estimation of urinary oxalate [7]. Hence gas chromatographic [8-10], high performance liquid chromatographic [11-13], ion pair chromatographic [14-15] methods have been developed for analysis of oxalate from biological fluids. The various other enzymatic [16$21]$, colorimetric $[22,23]$ and Isotachophoresis [24, 25] methods have been developed for analysis of oxalate from biological fluids and in the presence of oxalate concentration altering bio-molecules like ascorbic acid. Among all these methods, oxalate oxidase (00) method was most widely used as it was developed in the form of a colorimetric kit which will give accurate, robust and uniform result when you analyze the same at any centre over the entire globe.
Various laboratories have developed their high-performance liquid chromatography-based using a different setup (column, eluant, detector, retention time, etc) for estimation of oxalate content from native urine and urine spiked with oxalate and comparative profile of these methods has been evaluated by Zerwekh [26] Hesse [27], suggesting need of universal method for bio-analysis of oxalate. Most of the reported methods involve pre-analysis sample processing to achieve maximum oxalate content for analysis.

Hence there is need of simple method which will be universal for estimation of oxalate content from biological matrices otherwise such method needs relative standardization with previously developed method [28]. In this communication, we have proposed new high-performance liquid chromatography (HPLC) method for estimation of oxalate from biological matrices without preanalysis sample preparation which would be simple, accurate, precise, sensitive and selective for the same and useful over the entire globe.

\section{MATERIALS AND METHODS}

\section{Materials}

\section{Chemicals}

Acetonitrile, oxalic acid, methanol, acetic acid and distilled water (Loba Chemie Pvt. Ltd. Mumbai, India) of HPLC grade were used. The urine samples of healthy and kidney stone diseased human volunteers were collected in department of urology, Government Medical College, and Endo-Urology Centre, Gune's Nirmal Nursing Hospital, Kolhapur, Maharashtra, India with all ethical procedure and secured permission for this research work from Institutional Ethical Committee (IEC), National Centre for Cell Science (NCCS), Pune (Approved in thirteen meeting of IEC of NCCS, Pune). 


\section{Instruments}

\section{HPLC system}

The HPLC system used was a PC based Jasco series comprising of a pump PU-2080 (Dual piston with gear is driven pump) and a UV-2070 detector [29]. The UV detector used in this HPLC system was a czerny turner mount monochromator with deuterium lamp as the light source. Manual injections were carried out using a rheodyne injector with a fixed $20 \mu \mathrm{l}$ external loop. The chromatographic and the integrated data were recorded using a Hercule 2000 (interface) computer system. Data processing was carried out using Borwin software of 1.5 version.

\section{UV-visible double beam spectrophotometer}

Spectrophotometric analysis was carried out on Jasco model V-530 UVVisible double beam high-speed scanning spectrophotometer with a single monochromator with a 1200 grooves $/ \mathrm{mm}$ concave grating. The detector was silicon photodiode (S1337). Light sources used were deuterium lamp (190 to $350 \mathrm{~nm}$ ) and a halogen lamp (330 to $1100 \mathrm{~nm}$ ). The instrument had wavelength accuracy of $\pm 0.3 \mathrm{~nm}$ and baseline stability of $\pm 0.001 \mathrm{Abs} / \mathrm{h}$.

\section{Methods}

\section{Preparation of standard solutions of oxalic acid}

Fifty mg of HPLC grade pure oxalic acid was weighed accurately. It was then transferred to $50 \mathrm{ml}$ volumetric flask and volume was made up to the mark with pure methanol having concentration $1000 \mu \mathrm{g} / \mathrm{ml}$. It was then sonicated and used for method development. After method optimization, a solution of oxalic acid was prepared in mobile phase (methanol: $0.001 \mathrm{~N}$ acetic acid in water $(50: 50, \mathrm{v} / \mathrm{v})$ ) of same strength $(1000 \mu \mathrm{g} / \mathrm{ml})$.

\section{Selection of wavelength of analysis}

The standard stock solution was diluted to $10 \mu \mathrm{g} / \mathrm{ml}$. The wavelength of analysis of oxalic acid was selected by analyzing $10 \mu \mathrm{g} / \mathrm{ml}$ solution of same in pure methanol on UV-Visible double beam spectrophotometer over 200 to $400 \mathrm{~nm}$ wavelength range. The wavelength of $237 \mathrm{~nm}$ was selected having maximum absorbance.

\section{Collection of urine samples}

All study population inclusion of only male candidates, a total of 24 recurrent stone patients and 15 healthy subjects were included in the study population. The exclusion criteria were an active urinary infection, previous intestinal surgery, and intestinal disease. Patients who have already confirmed the nephrolithiasis by ultra-imagine; and none of the patients had received antibiotics or probiotic preparations in the 3 mo before enrollment. Subjects voluntarily accepted the study with consent. Institutional ethics committee approval had been obtained before the commencement of the study (other data). The urine samples of human volunteers were collected for method development and analysis over a period of $24 \mathrm{~h}$. as claimed by Naim [30] and Curhan [31]. These urine samples were refrigerated until its analysis. Neither preservative nor any processing was carried out on collected urine sample. It was then processed for analysis to determine oxalate content by HPLC.

\section{Chromatographic method development for oxalate analysis in} urine

The sample solution of oxalic acid in urine for method development was prepared by mixing $0.1 \mathrm{ml}$ of stock solution of oxalic acid in the mobile phase and $2 \mathrm{ml}$ of urine of healthy human volunteer and diluting it to $10 \mathrm{ml}$ with mobile phase. This solution was then injected to a chromatographic system with KYATECH HiQ Sil $\mathrm{C}_{18} \mathrm{HS}$ column using rheodyne injector at a flow rate of $1 \mathrm{ml} / \mathrm{min}$ and wavelength of analysis, $237 \mathrm{~nm}$. The oxalic acid was resolved at 2.7 min with good retention parameters under above chromatographic conditions. As the concentration of oxalic acid was calculated by single point calibration method, the same sample solution was then injected under similar conditions for 5 more times, and area of the oxalic acid peak was recorded using software. The mean of area of six readings of oxalic acid in urine was calculated, and concentration of oxalic acid in urine patient was calculated using following formula,

Oxalic acid content $(\mu \mathrm{g} / \mathrm{ml})=$ area of oxalate peak $/$ mean of area of 6
readings $\times 10$

The concentration of oxalic acid in $\mathrm{mg} / \mathrm{x} \mathrm{ml}$ of urine was calculated by multiplying above reading by dilution factor and $\mathrm{x}$.

Analysis of oxalate in quality control samples and in urine of volunteers

The quality control samples were prepared from standard stock solution and urine of healthy volunteers and analyzed by the same procedure is given above. The results are reported in table 1.

Table 1: Results of analysis of quality control samples, linearity and extraction recovery studies of oxalate

\begin{tabular}{|c|c|c|c|c|c|}
\hline \multicolumn{6}{|c|}{ Analysis of quality control samples and extraction recovery studies } \\
\hline Concentration (ng/ml) & & $\%$ Concentration estimated mean ${ }^{\mathrm{a}} \pm \mathrm{SD}^{\mathrm{b}}$ & \multicolumn{3}{|c|}{ \% Recovery estimated meanc \pm SD $^{b}$} \\
\hline 50 & & $85.65 \pm 1.4592$ & \multicolumn{3}{|c|}{$90.70 \pm 2.4174$} \\
\hline 150 & & $87.76 \pm 1.4208$ & \multicolumn{3}{|c|}{$89.16 \pm 1.8503$} \\
\hline 300 & & $87.84 \pm 1.0597$ & \multicolumn{2}{|c|}{$92.21 \pm 2.1824$} & \\
\hline \multicolumn{6}{|c|}{ Linearity and range study } \\
\hline Range in $\mathrm{ng} / \mathrm{ml}$ & Slope & Intercept & SEd of slope & $S E^{d}$ of intercept & Correlation coefficient \\
\hline $50-300$ & $3.357 \times 10^{-3}$ & $5.217 \times 10^{-2}$ & $3.024 \times 10^{-5}$ & $4.781 \times 10^{-4}$ & 0.9981 \\
\hline
\end{tabular}

${ }^{a}$ Average of five determinations, bStandard deviation, cAverage of four determinations, dStandard error

Analysis of urine of kidney stone patients and healthy volunteers for oxalate content was carried out by the method explained above without adding $0.1 \mathrm{ml}$ of stock solution of oxalic acid in the mobile phase. The results of analysis are reported in table 2 .

\section{RESULTS AND DISCUSSION}

The brief study of various types of chromatographic, spectroscopic methods emphasized the need of simple, accurate and universal method used for analysis of oxalate in a biological fluid, especially urine. The method was found to be satisfactory for analysis of oxalate from urine samples of human volunteers as after observing chromatogram; it can be concluded that most of other interfering components in human urine were not retained in optimized mobile phase except few. Even though, colorimetric or enzymatic methods were widely used for analysis, developed HPLC method was found to be simple as it required a minimum number of steps compared to these methods.

The sample collection of urine from kidney stone diseased patient and healthy volunteers was carried out over a period of $24 \mathrm{~h}$ as all of the stones from patients contain calcium and oxalate and urinary saturation with oxalate will occur over this period through metabolism [3]. Since, every metabolic workup includes measurement of calcium and oxalate concentrations in a $24 \mathrm{~h}$ urine collection, together with other key analytes [30, 31].

The chromatographic separations were performed on a $5 \mathrm{~mm}$ KYATECH HiQ Sil $\mathrm{C}_{18} \mathrm{HS}$ column $(250 \mathrm{~mm} \times 4.6 \mathrm{~mm}$ i.d., $5 \mu \mathrm{m}$ particle size), operating at ambient temperature. The standard stack solution of oxalic acid was prepared in pure methanol having concentration $100 \mu \mathrm{g} / \mathrm{ml}$. The method development was initiated by analyzing 10 
$\mu \mathrm{g} / \mathrm{ml}$ solution of oxalic acid in methanol on HPLC system. The spectrum of pure oxalic acid was not resolved with good retention parameters (capacity factor, resolution, tailing factor, the number of theoretical plates, etc) [32]. The oxalic acid was resolved in methanol: water $(50: 50, \mathrm{v} / \mathrm{v})$ mobile phase with good retention parameters. One ml of oxalic acid solution was then mixed with $1 \mathrm{ml}$ of healthy human urine, and this mixture was diluted to $10 \mathrm{ml}$ with methanol: water $(50: 50, \mathrm{v} / \mathrm{v})$. This mixture was then injected to HPLC system, and chromatogram was recorded, and it was not resolved with good retention parameters. After several trials, methanol: $0.001 \mathrm{~N}$ acetic acid in water (50:50, v/v), the mobile phase has resolved oxalic acid in a urine sample at a retention time of $2.705 \pm 0.005$ min with good retention parameters (fig. 1). Thus oxalic acid in urine sample was possible to quantify on $5 \mu \mathrm{m}$
KYATECH HiQ Sil $\mathrm{C}_{18} \mathrm{HS}$ column ( $250 \mathrm{~mm} \times 4.6 \mathrm{~mm}$ i.d.) at a flow rate of $1 \mathrm{ml} / \mathrm{min}$, at a wavelength of $237 \mathrm{~nm}$ using methanol: water $(50: 50, \mathrm{v} / \mathrm{v}) 0.001 \mathrm{~N}$ acetic acid mobile phase. The results of analysis obtained after analysis of urine sample from normal and healthy volunteers were found to be satisfactory and reliable, but this method needs to be validated. Hence validation of method has been carried out by respective guidelines.

In most of the methods, sample preparation for oxalate content required pre-acidification by acetic acid $[26,27]$ but in the present communication, we have used acetic acid as part of mobile which makes the method as there is no need of sample pre-processing step. This acetic acid has increased the concentration of oxalate which has been retained over the stationary phase.

Table 2: Result of determination of oxalate content in urine of healthy (HLT) and kidney stone diseased (KSD) volunteers

\begin{tabular}{|c|c|c|c|c|c|}
\hline $\begin{array}{l}\text { Volunteer } \\
\text { code }\end{array}$ & Number of stones & $\begin{array}{l}\text { Concentration } \\
\text { in } \mu \mathrm{g} / \mathrm{ml}\end{array}$ & $\begin{array}{l}\text { Volunteer } \\
\text { code }\end{array}$ & Number of stones & $\begin{array}{l}\text { Concentration } \\
\text { in } \mu \mathrm{g} / \mathrm{ml}\end{array}$ \\
\hline KSD_1 & 5 & 140.6024 & KSD_30 & 4 & 50.4328 \\
\hline KSD_2 & 6 & 70.9542 & KSD_31 & 6 & 120.2586 \\
\hline KSD_3 & 5 & 40.0254 & KSD_32 & 5 & 60.9981 \\
\hline KSD_4 & 4 & 60.1502 & KSD_33 & 4 & 50.6925 \\
\hline KSD_7 & 7 & 80.8047 & HLT_1 & 0 & 2.0875 \\
\hline KSD_9 & 5 & 100.6679 & HLT_2 & 0 & 3.8035 \\
\hline KSD_10 & 5 & 70.4897 & HLT_3 & 0 & 0.5784 \\
\hline KSD_12 & 8 & 50.9875 & HLT_4 & 0 & 2.7721 \\
\hline KSD_13 & 4 & 130.8206 & HLT_5 & 0 & 2.1589 \\
\hline KSD_14 & 4 & 90.5782 & HLT_6 & 0 & 1.9029 \\
\hline KSD_20 & 5 & 80.2496 & HLT_7 & 0 & 0.8565 \\
\hline KSD_21 & 6 & 150.2171 & HLT_8 & 0 & 11.4752 \\
\hline KSD_22 & 4 & 50.6745 & HLT_9 & 0 & 0.8812 \\
\hline KSD_23 & 5 & 50.8762 & HLT_10 & 0 & 0.4785 \\
\hline KSD_24 & 4 & 70.9864 & HLT_11 & 0 & 10.1217 \\
\hline KSD_25 & 3 & 120.9987 & HLT_12 & 0 & 6.7485 \\
\hline KSD_26 & 5 & 60.3574 & HLT_13 & 0 & 0.8979 \\
\hline KSD_27 & 6 & 70.6348 & HLT_14 & 0 & 3.2486 \\
\hline KSD_28 & 5 & 60.0269 & HLT_15 & 0 & 0.0573 \\
\hline KSD_29 & 4 & 50.3985 & & & \\
\hline
\end{tabular}

The sample chromatograms of analysis of healthy volunteer and kidney stone patient urine are shown in fig. 1.

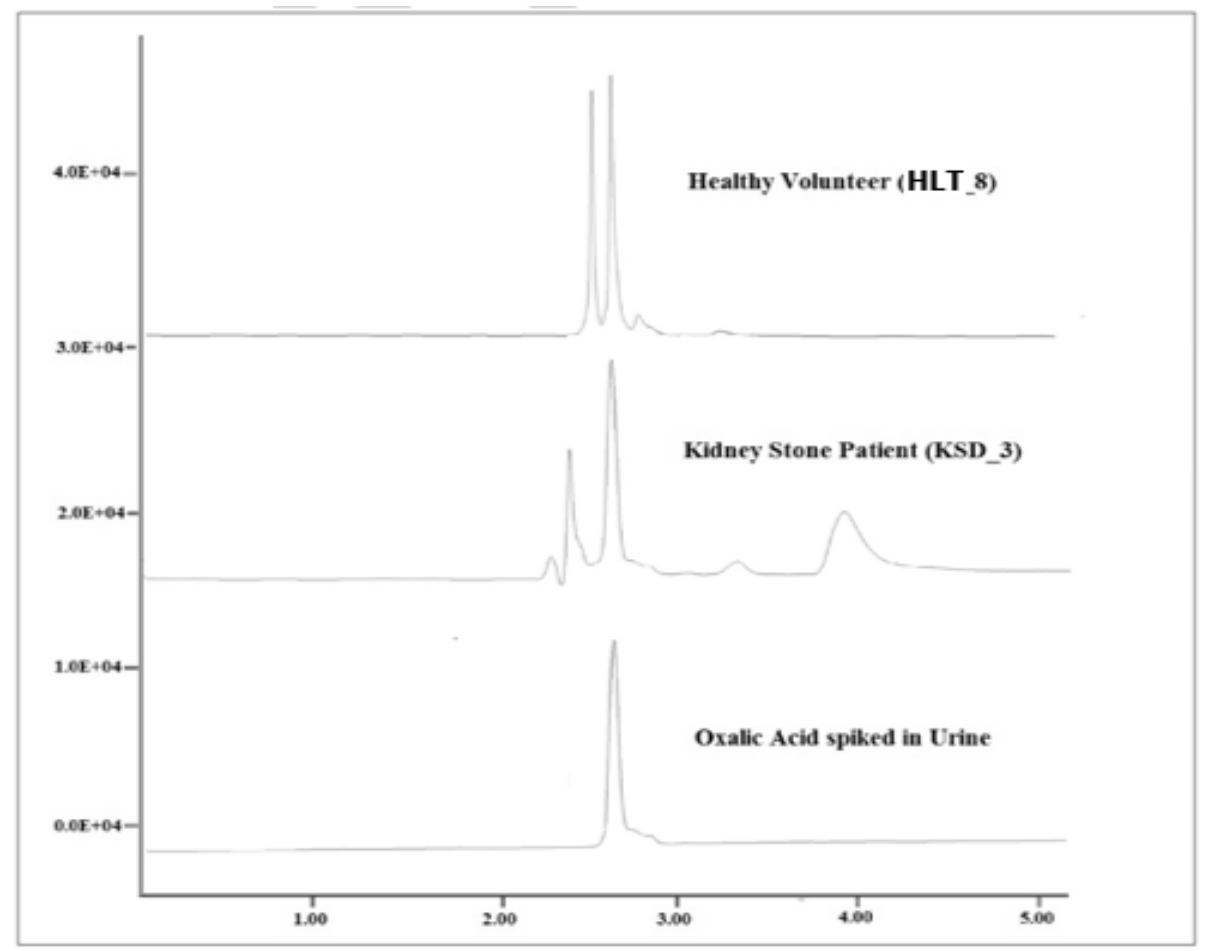

Fig. 1: Chromatograms of oxalic acid in various urine samples 


\section{Validation of chromatographic method}

The validation of developed method was carried out by USFDA guidelines for bioanalytical method validation [33, 34]. The validation of method was carried out by performing following studies.

\section{Selectivity}

Individual specificity, in relation to endogenous urine components, was demonstrated by analysis of series of randomly selected oxalic acid-free urine samples. Typical chromatograms obtained after analysis of oxalic acid-free urine and urine samples after addition of oxalic acid are reported in fig. 2 .
The retention time for the investigated oxalic acid was found to be different than that of endogenous urine components. Thus, it indicates selectivity of a method for elution of oxalic acid in urine.

\section{Linearity and range study}

The response factors calculated were found to be proportional to concentrations of analytes over the ranges tested as specified in table 1 . This study was carried out separately on three consecutive days. The calibration curves were fitted by method of least square. The results of linearity study by regression analysis are given in table 1.

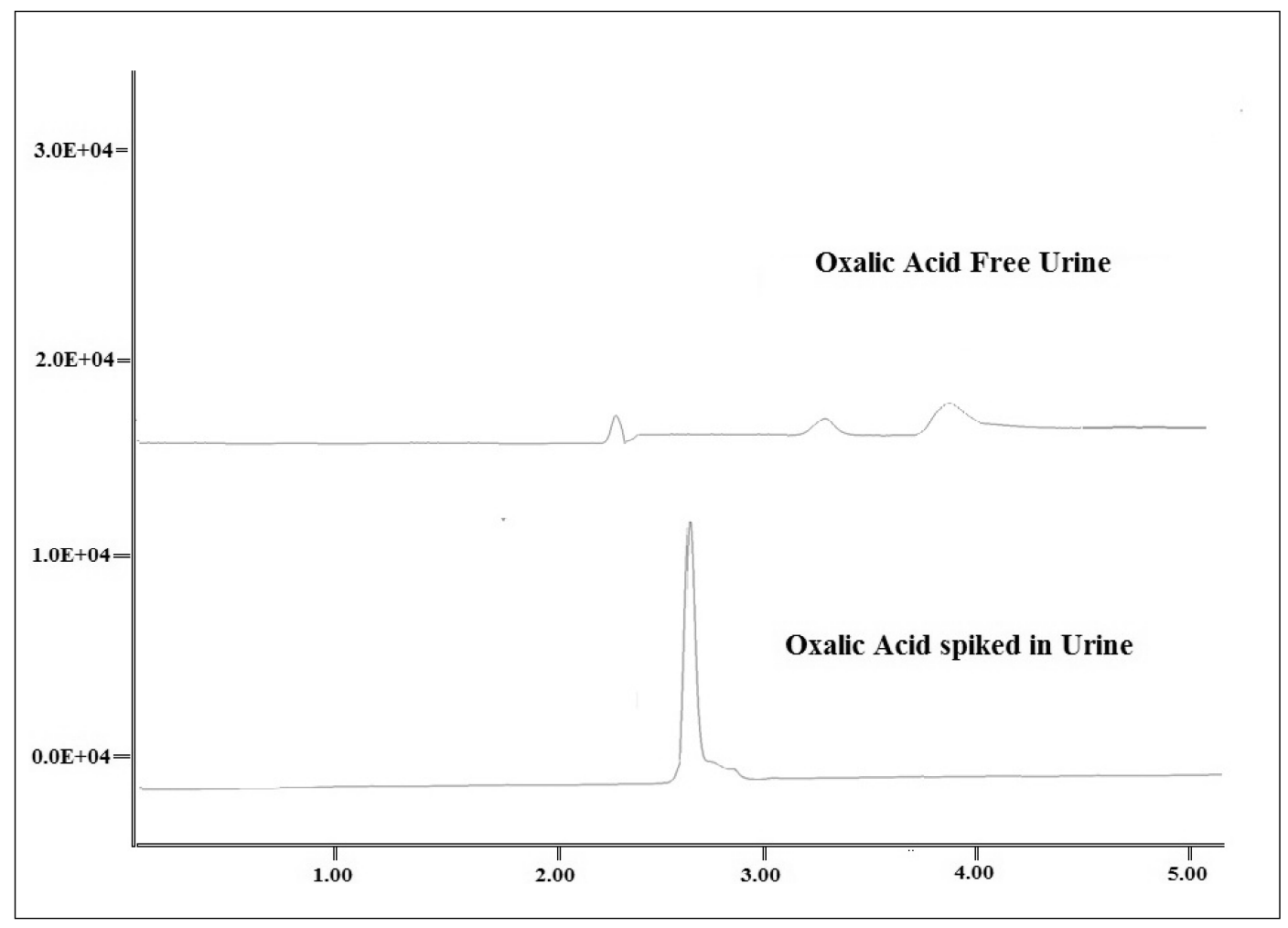

Fig. 2: Selectivity study of method by analyzing oxalic acid-free urine and oxalic acid spiked in urine

\section{Lower limit of quantitation (LLOQ)}

It is the lowest serum concentration of oxalic acid quantified with a coefficient of variation of less than $20 \%$. The LLOQ value of oxalic acid was found to be $49 \mathrm{ng} / \mathrm{ml}$.

\section{Accuracy study}

The recovery study has been carried out by analyzing quality control samples, (five determinations per three concentrations) spiked with the analyte. Results of accuracy study are given in table 3 .

Table 3: Result of accuracy and precision studies

\begin{tabular}{|c|c|c|c|c|}
\hline Analyte & Precision & & Amount of pure oxalic acid added & $\%$ Concentration estimated mean ${ }^{\mathrm{a}} \pm \mathrm{SD}^{\mathrm{b}}$ \\
\hline \multirow[t]{6}{*}{ Oxalate } & Intra-day & $\mathrm{T} 1$ & $5 \mathrm{mg}$ & $89.44 \pm 2.6215$ \\
\hline & & $\mathrm{T} 2$ & $10 \mathrm{mg}$ & $92.46 \pm 4.1412$ \\
\hline & & T3 & $15 \mathrm{mg}$ & $91.56 \pm 3.0555$ \\
\hline & Inter-day & D1 & - & $90.57 \pm 3.0648$ \\
\hline & & D2 & - & $90.25 \pm 1.1468$ \\
\hline & & D3 & - & $90.28 \pm 1.4562$ \\
\hline
\end{tabular}

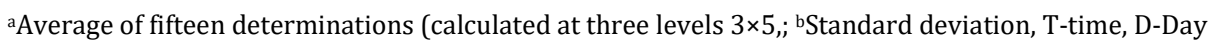

\section{Extraction recovery studies}

The recovery represents the efficiency of an analytical method within the variation limit. The recovery in an assay is the detector response obtained from an amount of analyte added and recovered from the biological matrix (urine). Recovery experiments performed in quadruplicate for an analyte by comparing the analytical results for extracted samples at three concentrations (equivalent to LLOQ MQC, and HQC) with three unextracted concentrations that represent $100 \%$ recovery.

Results of the extraction recovery for analyses are given in table 1 . 
MQC-medium quality control concentrations, 50\% of largest concentrations of calibration curve (linearity study)

HQC-high quality control concentrations, 75-90\% of largest concentrations of calibration curve (linearity study)

$\%$ recovery $=($ Mean response of extracted samples $/$ Mean response of un-extracted samples) $\times 100$ [35].

\section{Precision study}

The precision study was carried out by analyzing the urine samples of three concentrations specified in the inaccuracy study for three consecutive days at two different times. This analysis illustrates the intraday and interday precision study. The urine samples were stored in between analysis in a freezer at- $17{ }^{\circ} \mathrm{C}$. The results of the precision studies are reported in table 3.

\section{Stability study}

This study was carried out by performing analysis of stock solutions, unextracted urine samples, and freshly prepared solutions at various atmospheric conditions and times as shown in the following headings as per guidelines as the mean of 6 readings with its standard deviation [36, 37].

\section{Stock solution stability}

To test the stock solution stability of oxalic acid, five aliquots of standard stock solutions were left at- $17{ }^{\circ} \mathrm{C}$ for $3 \mathrm{~d}$. Then, the concentrations were analyzed and compared with the fresh stock solution. The percentage recovery of oxalic acid was found to be $99.73 \pm 1.97$ (mean \pm standard deviation).

\section{Freeze and thaw stability}

The effect of freeze and thaw cycles on the stability of urine samples containing analytes were determined by subjecting five aliquots of quality control (QC) samples at low, middle, and high concentration unextracted quality control samples to four freeze-thaw cycles. After completion of every cycle, the samples were analyzed, and the experimental concentrations were compared with the nominal values obtained by analyzing fresh samples. The accuracy values of three concentrations in two freeze-thaw cycles were calculated. The percentage recovery of oxalic acid was found to be $99.46 \pm 3.57$ (mean \pm standard deviation).

Short-Term Stability-Five aliquots of QC samples at low, mid, and high concentration unextracted QC samples were kept at ambient temperature $\left(15^{\circ} \mathrm{C}\right)$ for $12 \mathrm{~h}$ in order to determine the short-term stability of analytes in urine. Then, the samples were processed and analyzed and the concentrations obtained were compared with the nominal values obtained by analyzing fresh samples. The percentage recovery of oxalic acid was found to be $100.23 \pm 2.25$ (mean \pm standard deviation).

\section{Post-preparation stability}

In order to estimate the stability of oxalic acid in the prepared samples, five aliquots of QC samples at low, mid, and high concentration were kept at $4{ }^{\circ} \mathrm{C}$ for about $4 \mathrm{~h}$. Then, the samples were analyzed and the concentrations obtained were compared with the nominal values obtained by analyzing fresh samples. The percentage recovery of oxalic acid was found to be $100.16 \pm 3.98$ (mean \pm standard deviation).

\section{CONCLUSION}

The developed method was found to be accurate, precise, sensitive and selective for quantification of oxalate from the urine of kidney stone diseased patient and healthy volunteers. The method did not require pre-analysis sample processing as acetic acid is part of the mobile phase, used to concentrate oxalate in biological matrices. This method will be useful for estimation of oxalate from other biological matrices with few optimizations. The oxalate content data generated in this communication (table 2) was used for characterizing the gut microbial diversity of recurrent stone patients and healthy male subjects in comparatives by means diazotrophic bacterial colonization pattern and oxalate content in urine within into it.

\section{ACKNOWLEDGEMENT}

Mr. Mangesh Suryavanshi acknowledges a research fellowship from the Council of Scientific and Industrial Research (CSIR). Mr. Mangesh Suryavanshi and Dr. Yogesh Souche have gratitude towards the Department of Biotechnology, Government of India for 'Microbial Culture Collection' project. All authors are thankful to Principal, Bharati Vidyapeeth College of Pharmacy, Kolhapur, India for providing facilities for this research work. The authors are also thankful to human volunteers who actively participated for this research work.

\section{CONFLICTS OF INTERESTS}

Declared none

\section{REFERENCES}

1. Lotan Y, Cadeddu JA, Pearle MS. International comparison of cost effectiveness of medical management strategies for nephrolithiasis. Urol Res 2005;33:223-30.

2. Robertson WG, Peacock M. The cause of idiopathic calcium stone disease: hypercalciuria or hyperoxaluria? Nephron 1980;26:105-10.

3. Daudon M, Dore JC, Jungers P. Changes in the stone composition according to age and gender of patients: a multivariate epidemiological approach. Urol Res 2004;32:241-7.

4. Zimmermann DJ, Hesse A, Von Unruh GE. Influence of a highoxalate diet on intestinal oxalate absorption. World J Urol 2005;23:324-9.

5. Pak CY, Adams-Huet B, Poindexter JR. The relative effect of urinary calcium and oxalate on the saturation of calcium oxalate. Kidney Int 2004;66:2032-7.

6. Finkielstein VA, Goldfarb DS. Strategies for preventing calcium oxalate stones. CMAJ-JAMC Practice 2006;174:1407-9.

7. Mazzachi B, Teubner J, Ryall R. Factors affecting the measurement of urinary oxalate. Clin Chem 1984;30:1339-43.

8. Farrington CJ, Chalmers AH. Gas-chromatographic estimation of urinary oxalate and its comparison with a colorimetric method. Clin Chem 1979;25:1993-6.

9. Yanagawa M, Ohkawa H, Tada SJ. The determination of urinary oxalate by gas chromatography. Urologie 1983;129:1163-5.

10. Moye HA, Malagodi MI, Clarke DH, Miles CJ. A rapid gas chromatographic procedure for the analysis of oxalate ion in urine. Clin Chim Acta 1981;114:173-85.

11. Hughes H, Hagen L, Sutton RAL. Determination of urinary oxalate by high-performance liquid chromatography. Anal Biochem 1982;119:1-3.

12. Larsson L, Libert B, Asperud M. Determination of urinary oxalate by reversed-phase ion-pair "high-performance" liquid chromatography. Clin Chem 1982;28:2272-4.

13. Honow R, Bongartz D, Hesse A. An improved HPLC-enzymereactor method for the determination of oxalic acid in complex matrices. Clin Chim Acta 1997;261:131-9.

14. Robertson WG, Scurr DS, Smith A, Orwell RL. The determination of oxalate in urine and urinary calculi by a new ion-chromatographic technique. Clin Chim Acta 1982;126:91-9.

15. Menon M, Mahle CJ. Ion-chromatographic measurement of oxalate in unprocessed urine. Clin Chem 1983;29:369-71.

16. Costello J, Hatch M, Bourke E. An enzymic method for the spectrophotometric determination of oxalic acid. J Lab Clin Med 1976;87:903-8.

17. Yriberi-i J, Posen S. A semi-automatic enzymic method for estimating urinary oxalate. Clin Chem 1980;26:881-4.

18. Potezny N, Bais R, O'Loughlin PD. Urinary oxalate determination by use of immobilized oxalate oxidase in a continuous flow system. Clin Chem 1983;29:16-20.

19. Buttery JE, Ludvigsen N, Braiotta EA, Pannall PR. Urinary oxalate determination by use of immobilised oxalate oxidase in a continuous-flow system. Clin Chem 1983;29:700-2.

20. Obzansky DM, Richardson KE. Quantification of urinary oxalate with oxalate oxidase from beet stems. Clin Chem 1983;29:1815-9.

21. Kohlbecker G, Richter L, Butz MJ. Determination of oxalate in urine using oxalate oxidase: comparison with oxalate decarboxylase. Clin Chem Clin Biochem 1979;17:309-13. 
22. Hodgkinson A, Williams A. An improved the colorimetric procedure for urine oxalate. Clin Chim Acta 1972;36:127-32.

23. Baadenhuijsen $\mathrm{H}$, Jansen AP. Colorimetric determination of urinary oxalate recovered as calcium oxalate. Clin Chim Acta 1975;62:315-24.

24. Schmidt K, Hagmaier V, Bruchelt G, Rutishauser G. Analytical isotachophoresis: A rapid and sensitive method for determination of urinary oxalate. Urol Res 1980;8:177-80.

25. Schwendtner N, Achilles W, Engelhardt W. Determination of urinary oxalate by isotachophoresis. Practical improvement and critical evaluation. J Clin Chem Clin Biochem 1982;20:833-6.

26. Zerwekh J, Drake E, Gregory J. Assay of urinary oxalate: six methodologies compared. Clin Chem 1983;29:1977-80.

27. Hesse A, Bongartz D, Heynck H. Measurement of urinary oxalic acid: a comparison of five methods. Clin Biochem 1996;29:467-72.

28. Naim MM, Beverley AH, Andreas P. Variability in urinary oxalate measurements between six international laboratories. Nephrol Dial Transplant 2011;1:1-6.

29. Kumbhar ST, Jadhav SD, Bhatia NM, Bhatia MS. Development and validation of a derivative spectrophotometric method for estimation of atorvastatin calcium and amlodipine besylate in tablet dosage form. Int J Pharm Pharm Sci 2011;3:195-7.

30. Curhan GC, Willett W, Speizer FE. Twenty-four-hour urine chemistries and the risk of kidney stones among women and men. Kidney Int 2001;59:2290-8.
31. Taylor EN, Curhan GC. Determinants of 24-hour urinary oxalate excretion. J Am Soc Nephrol 2008;3:1453-60.

32. Snyder LR, Kirkland JJ, Glajch JL. Practical method development. 2nd edition. Hoboken: John Wiley and Sons, Inc.; 1997.

33. Center for Drug evaluation and Research. U. S. Department of Health and Human Services. Guidance for Industry: Bioanalytical Method Validation. Rockville MD: FDA; 2001.

34. Mukti Aa, Jannah F, Nurrochmad A, Lukitaningsih E. Development and validation method for quantitative determination of ciprofloxacin in human plasma and its application in bioequivalence test. Asian J Pharm Clin Res 2016;9:89-95.

35. Pal PK, Ganesan M. Bioavailability, and bioequivalence in pharmaceutical technology. New Delhi: CBS Publishers and Distributors; 1999.

36. Division of Communications Management, Center for Drug Evaluation and Research (CDER). Reviewer Guidance: Validation of Chromatographic Methods. Rockville, MD: CDER, FDA; 1994.

37. Ferraz RR, Baxmann AC, Ferreira LG. Preservation of urine samples for metabolic evaluation of stone-forming patients. Urol Res 2006;34:329-37.

\section{How to cite this article}

- Mangesh V Suryavanshi, Swapnil D Jadhav, Rahul P Gune, Manish S Bhatia, Yogesh S Shouche. HPLC analysis of human urine for oxalate content. Int $\mathrm{J}$ Pharm Pharm Sci 2016;8(12):54-59. 